\title{
Article
}

\section{Safe Haven-Bath House and Library by the Burmese Border}

\author{
Anett Mizsei ${ }^{1, *}$ and Péter György Horváth ${ }^{2}$ \\ 1 Ybl Miklós Faculty of Architecture and Civil Engineering, Óbuda University, Budapest, 1034 Gyor, Hungary \\ 2 Simonyi Károly Faculty of Engineering, University of Sopron, Sopron, 9400 Gyor, Hungary; \\ horvath.peter.gyorgy@uni-sopron.hu \\ * Correspondence: mizsei.anett@ybl.uni-obuda.hu; Tel.: +36-70-340-16-50
}

Citation: Mizsei, A.; Horváth, P.G. Safe Haven-Bath House and Library by the Burmese Border. Heritage 2021, 4, 2105-2123. https://doi.org/ 10.3390/heritage4030119

Academic Editors: Éva Lovra and Nicola Masini

Received: 13 July 2021

Accepted: 30 August 2021

Published: 2 September 2021

Publisher's Note: MDPI stays neutral with regard to jurisdictional claims in published maps and institutional affiliations.

Copyright: (C) 2021 by the authors. Licensee MDPI, Basel, Switzerland. This article is an open access article distributed under the terms and conditions of the Creative Commons Attribution (CC BY) license (https:// creativecommons.org/licenses/by/ $4.0 /)$.

\begin{abstract}
This study gives an overview of contemporary vernacular tendencies in Thai architecture. The research includes ecological, economical, ergonomic and cultural aspects, and the aim is to find a possible future direction for architectural design that is able to incorporate local features and follow traditions yet apply them in a contemporary way. As an example, a case study was carried out about a project realized in Safe Haven Orphanage in Thailand. It consists of two small-scale buildings designed and constructed by TYIN Tegnestue Architects, Sami Rintala and Hans Skotte, together with volunteers and the local community, and they are great examples of a community building "healing architecture". Due to their aesthetics, their ecological and sustainable approach and their structures, they can provide cultural continuity, which is key for the organic evaluation of regional architecture.
\end{abstract}

Keywords: architecture; healing architecture; ergonomics; community building; ecology; architecture for children; low-tech; universal design; vernacular architecture; regionalism

\section{Introduction}

The core question of this research is what design and construction methodologies can be applied to create projects on a small scale, yet with great added value, with no standards and regulations and almost no sources for construction and maintenance present. The answer may lie in a rather underrepresented branch of architecture, which puts the real needs of users first, opting for low-tech solutions and considering local cultural, climatic and social characteristics and creating a balance between ecology and human comfort.

The location chosen for this study is Central-Western Thailand. The traditional architecture and technologies specific for this region were well alive back in the 1970s. However, "rapid urbanization and economic development of the countries in the region led to a massive destruction of these buildings and replacement by modern types at the beginning of the 1990s" [1]. This international style of contemporary architecture lacks the values and cultural content that traditional architecture owns in regards of comfort, ecology, economy and aesthetics [2]. In contradiction, in Western countries, this 20-year period was exactly the era of professionals and thinkers of the field rediscovering the ecological and aesthetical values in vernacular architecture [1]. It was not until the early 2010s that "the vulnerability of vernacular traditions under the threat of modern developments is the issue most commonly addressed, used as object of research and applied to policy" [3]. According to publications, the damage in architectural heritage was the greatest in rural areas-particularly smaller, traditional residential buildings-compared to important national monuments, acknowledged and protected more efficiently and effectively [unige]. As a conclusion of studies and articles [1-3] on this era, it is clear that copying Western patterns without adapting them to local needs led to a significant tangible (actual buildings) and intangible (technology, traditional building methods and knowledge) loss, in addition to decreasing comfort for users.

Ergonomics, as a discipline, is present in all phases of product design and manufacturing and has an extensive literature in academia. The aim of the ergonomic approach is to 
optimize human-product interactions, i.e., to make human activity more efficient, safer, more comfortable and more satisfactory in all respects [4] when producing or using the product, service or process.

Focusing on the concept of ergonomics in the field of architecture, it can be said that a number of ergonomic aspects are fixed through various regulations: in order for a building to be realized, it is necessary to comply with current legislation, which is often based on ergonomic and anthropometric data. Design decisions are therefore possible only within this legal framework, considering the given task, the needs of future users and the available resources. Creative freedom primarily covers aspects not included in law [5]. The interesting thing about the two projects chosen as the subjects of this case study is that they were built in a location with significantly less regulations than in Europe or North America. Such a situation - in addition to the freedom of design —-means a great responsibility for all participating creators. At the same time, it provides an opportunity to work more closely with the user group, to recognize real needs and to serve them in as many ways as possible (Figure 1).

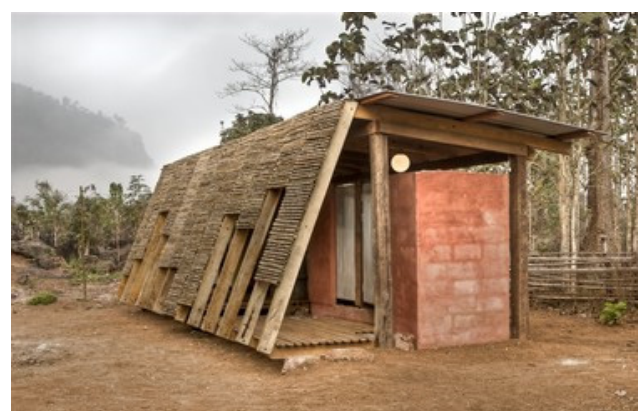

(a)

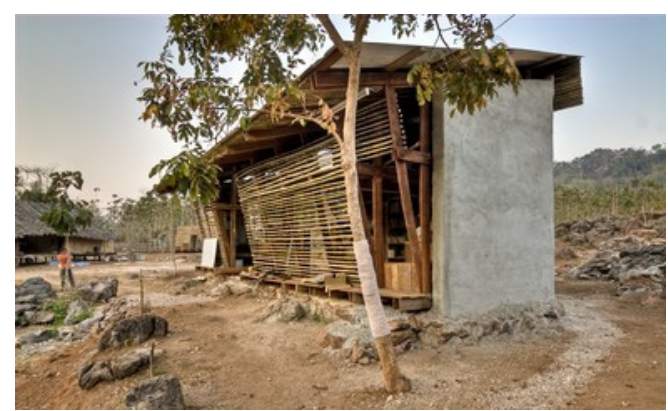

(b)

Figure 1. (a) Picture of the Bathhouse. Photo of Safe Haven Bath house, photo: Pasi Aalto, architecture: TYIN Tegnestue (Andreas G. Gjertsen, Yashar Hanstad), Available online: http:/ /www.tyinarchitects.com/download/works/2009 _safehavenbathhouse/01_safehavenbathhouse_photos_hires.Zip (accessed on 13 July 2021). (b) Picture of the Library. Photo of Safe Haven Library, photo: Pasi Aalto, architecture: TYIN Tegnestue (Andreas G. Gjertsen, Yashar Hanstad), Available online: http://www.tyinarchitects.com/download/works/2009_safehavenlibrary/01_safehavenlibrary_photos_hires.zip (accessed on 13 July 2021).

The aim of this paper is to study two contemporary buildings of the Safe Haven orphanage in Burma (designers: TYIN Tegnestue Architects, Sami Rintala, Hans Skotte) based on the methodologies and analytical aspects presented in the above sources. In this case, it is not simply a kindergarten or school environment, but provides home for a traumatized, injured and vulnerable group, where the cooperation and community building mentioned above are of increased importance. At the same time, the financial resources were limited, so the project is also a good example of low-tech and low-cost architecture based on local traditions and heritage, realized through cooperative construction. Such projects, although small in size, become more and more valuable in our time and provide new ways for architecture that allow for a more harmonious coexistence of people, design and environment while fulfilling important social missions. The two projects are chosen to represent the significance of ergonomics in architecture, both in the physical and psychological points of view. In addition, they might be a possible future direction for vernacular design, adopting and keeping local traditions alive in a contemporary way.

\section{Materials and Methods-Theoretical Background}

The aim of this study is to analyze two buildings created for a special group of children (orphaned Burmese refugee children) and their mentors, caregivers and teachers. Three main aspects are to be considered: ergonomics, ecology (including economy and 
sustainability) and connection to regional architecture. This chapter includes theoretical background and an overview of publications on these topics.

The most important question is how traditional knowledge and technologies-regional architectural features - can be preserved in a contemporary way. Is there any method that leads back to the sustainable and environmentally conscious way of building and living, without impacting the comfort and well-being of users? These issues are essential to solve in order to prevent further damage and loss of valuable architectural heritage. Meanwhile it opens up the possibility to develop contemporary vernacular buildings, which evolve from that heritage, fits in local cultural patterns, and still meet the challenges of the $21^{\text {st }}$ century.

\subsection{Ecological Aspects}

In the second half of the 20th century, mass production and consumption, mobility, energy demand and, with it, emissions of pollutants and waste have reached alarming proportions. The 1970s brought a widespread recognition that a change of approach was needed in industry, design and even everyday life to offset the environmental damage caused by the above. Reducing size and quantity, while raising awareness for quality and design for the whole lifecycle of products have slowly come to the forefront of interest of product designers and architects: a new design paradigm has begun to take shape. Parallel to this, a number of other sectors have also begun to discover a more ecological approach, considering sustainability and the human-nature relationship. This ecological approach came hand-in-hand with the rising appreciation of vernacular architecture and traditional knowledge, as pointed out in the introduction.

In 1973, Ernst Schumacher published his book Small is Beautiful-Economics as if People Mattered, in which he defined the principles of a new, humane economics. He asks himself what is really required from scientists and technologists in these times and answers in three points that became the core of his work. These characteristics of methods, technology and equipment are that they are affordable and accessible to everyone, suitable for small-scale application and also relate to people's creativity [6]. These postmodern ideas are the basics of post-industrial society, and they soon swept through architectural theory and practices, too. In addition to high-tech solutions, architects rediscovered local, traditional solutions, and a wider discussion started about people's real needs. In Northern Europe, the theoretician, professor and architect Juhani Pallasmaa was one of the most important representatives of this field.

It is no wonder that Sami Rintala and his collegues, who studied in Pallasmaa's workshop, have been leading their practices according to those principles. Rintala approaches all of his projects as eco-design experiments, especially focusing on the relationship between man and nature. In most cases, the key is to break down the sharp line between the built and the natural environment in order to guide people back to their origins and make them aware that they are still a part of it. However, his ecological thinking does not end in this poetic attitude. He strives to create reasonable buildings: the first and most important step in sustainability is to reduce size in all cases. Instead of the needs created by the media and the consumer world, it researches one's real needs and desires-understanding this is key to creating a reasonable scale and comfort [7]. It is a very important point to consider when helping people of different cultures. Bare import of technology has its risks and setbacks. Despite good intentions, they may cause more harm than benefit when the result is foreign to local culture. The outcome might cause psychological and sustainability issues which cannot easily be solved later and which Thailand (alongside many other developing regions of the world) is already suffering from.

\subsection{Ergonomics}

In recent decades, the architectural profession has begun to acknowledge the importance of ergonomics and its own shortcomings in this field. Emerging social sensitivity, a demand for a more inclusive environment for groups or individuals with altered abilities, 
have put aspects of ergonomics at the focus of research. For example, comprehensive anthropometric databases have been developed, such as Childata, Adultdata and Olddata (Department of Trade and Industry), published between 1995 and 1998. Recent possible publications on the subject analyze these issues in a complex way, especially in areas of social importance such as hospitals and educational institutions. In many cases, their authors formulate specific methodologies to aid design $[4,5,8]$. It is increasingly common for the field of ergonomics to be extended beyond physically measurable anthropometric scaling to include psychological, spiritual or cultural factors [9-11].

In addition to the importance of individual design decisions and attitudes, the implementation of ergonomic design also depends on factors such as available basic data, that designers rely on, or local regulations in place. In addition, sustainability issues need to be mentioned here. By the 21st century, ecology has become an unavoidable ethical and design aspect, while the comfort, health and well-being of users are not to be compromised for the sake of environmentally friendly construction. One of the most important tasks of architecture is to reconcile these two aspects along a new paradigm that allows for the well-being and harmonious coexistence of man and nature [12]. As another study points out, "an environment-friendly building design cannot neglect the fact that building users are themselves part of the environment" [4]. From another point of view, the leading rating systems for the building's sustainable performance, such as LEED, as an example, mentions ergonomics as part of their strategy, these indicators are rather focusing on human interactions with specific elements or equipment, not buildings as a whole [4].

Similar ideas are expressed by Finnish architect-theorist Juhani Pallasmaa: "The essential mental task of architecture is accommodation and integration" [11]. Dwelling-in other terms "existence" itself-is closely related to the primary function of the building, but it is also more than that: "Architecture articulates the experiences of being-in-the world and strengthens our sense of reality and self" [11]. In order to establish this integration, the building should not draw a sharp boundary between external (natural) and internal (artificial) spaces [9]. In the design practice of Pallasmaa's student Sami Rintala, these transitional spaces are the key: the surrounding natural landscape can be experienced from there, in contrast of the seclusion and loneliness of the interior. Otherwise, this transition space induces a dialogue between the building, its user and its environment [7].

Although there is no comprehensive design methodology that is universally applicable, available publications from recent years have set out certain principles and factors that are key to the design of a product in terms of ergonomics. In addition, these were the basis of the design methodology of the architects, who created the two projects.

1. Involving users in the design process not only makes the designer's job easier, but also increases user satisfaction during the whole lifespan of the building.

2. Empathy: the diversity of people and their abilities must be taken into account. In addition to physical requirements, mental, psychological and cultural factors also play an important role, although there is usually less focus on them.

3. The mechanical application of stereotypes and standards is a bad practice. Usually, regulations are based on categories and standardization, unable to serve the real needs and abilities of people. Instead of relying only on standards and stereotypes, a systemoriented approach is needed, with consideration of the effect that the environment as a whole has on the actual people using it.

4. A holistic design approach is required instead. In the case of the built environment, this should take into consideration not only the main function of the building or its structures, but all the expected activities that future users might perform [4].

The political crisis in Burma, as in most wars, has serious consequences for the population to this day. Many children lose their families or find themselves in a hopeless situation from which only outside help can provide a way out. The Safe Haven orphanage was established to heal physical and mental injuries and to build a better future for those it cares for [13]. The events these children experience-the loss of their families, leaving their homes-are traumas that affect their sense of security, their socialization, their image of 
themselves and their place in the world in the long run. All this makes the ergonomics of their environment a high priority, especially regarding psychological and cultural factors. During the planning, all user groups must be taken into account with all their physical and mental needs, social background and past [4]. Therefore, caregivers and teachers are also to be considered the primary users of the building, alongside children. For children to feel safe and develop in a healthy way, they must have a loving relationship with at least one adult, and that adult must be present in their lives regularly [10]. The formation of these bonds should and can be supported by good design. In the case of children, the improper or inaccurate use of buildings and equipment must also be taken into account as their foresight of the possible consequences is limited. Beyond safety, a comfortable environment adapted to a child's scale promotes physical development and should always be shaped by ergonomics [9]. Of course, the users who maintain and operate the building also need to have an effective and safe work environment.

An environment that meets the needs of children (especially in the preschool age group) is challenging and stimulating for children with different perceptible textures, sounds, lights and colors. A diverse and multisensorial spatial system can serve them well. Quiet places serve for individual studying, more open community spaces for group activities and a completely open outdoor area for freedom of movement and physical development. There are four basic aspects to nursery architecture: space, scale and proportions, colors and lighting [10].

The psychological aspect of spaces created for children is also a major issue. More and more articles are considering it as equally important as the physical aspects of ergonomics: "involving the compliance of the product with the needs of physical compatibility (anthropometric, biomechanical and perceptive) of safety, well-being, and finally of value-emotional and subjective - that the individual-user attributes to his relationship with the product" [14]. In carefully shaped spaces, children's spatial intelligence develops, as the space stimulates and directly influences their behavior, thinking, feelings and imagination [4]. Architecture creates certain frameworks for our lives, our existence. A carefully designed environment for children provides space for physical, social, emotional, linguistic and cognitive development. Four main aspects can be distinguished for this purpose: movement, comfort, competence and control. A variety of possible movements and activities are the core of both muscular and intellectual development. In addition, spatial orientation and the development of healthy boundaries are related to the spaces provided for them. The comfort of the place involves the proper amount of stimulation for all senses. A supportive environment helps children to develop the feeling of competence: they can explore, use and live the space freely and independently if the space in question is designed with the correct features for each activity or function. Control is both about safety and the children's own experience of being in charge for their own actions. Design should consider the safety and access of the caretakers as well as the privacy of children [10]. To sum up, a safe and ergonomically designed space not only motivates children but also sets limits. These constraints can be realized on two levels: on the one hand, through the building's own design, and on the other hand, by providing the supervisor control over the situation with the appropriate vision, acoustics and accessibility.

Isenberg and Jalongo state similarly in their five criteria that architectural design:

1. conveys a message to children about desirable behaviors;

2. provides and facilitates freedom of movement;

3. encourages creative learning processes;

4. provides educators with supervision and guidance for children;

5. with the accessibility of different materials, tools and toys and with their openness from the child's point of view, it creates not only free play, but also a sense of possession and ownership of one's own little world in children [9].

When it comes to architecture, according to publications from the past decades, there seems to be a tendency for professionals of the field to become more and more aware of the significance of ergonomics and adapting and researching it with a holistic approach. 
In addition to the physical and psychological aspects, sustainability also became part of the discussion. Very few of them mention, however, the importance of local cultural and architectural heritage and mainly focus on historical aspects [15]. This article is therefore aimed to emphasize how cultural and architectural heritage of a specific area can induce a balance between ergonomics and sustainability, meanwhile exploring the design methodology which made it possible to connect them.

\subsection{Traditional Architecture in the Region and Contemporary Vernacularity}

The archetype of traditional house in this region evolved from early examples, that date back in the 13th century. There are basically two types:

1. houses floating on the water surface;

2. standing on stilts, located on riverbanks or lands.

The latter can be temporary/semi-permament, usually built from bamboo, or permanent and made of wood [3]: "The traditional Thai house is ideally adapted to its environment. Open high-pitched roof that facilitates air circulation. Open windows and walls in combination with a large central terrace provide ideal ventilation and offer relief from the hot and humid climate. Wide overhanging eaves protect the house from sun and rain. Rainwater runs off the steep roof quickly and falls through the permeable terrace and house floors" [2]. From another point of view, vertically, these buildings consist of three main parts: the roof, the floor structure built on stilts and the living area enclosed by the two [16].

Raised floors serve more than one function. It provides optimal ventilation, protects the interior from flooding waters [17] and marks the different functional zones of the house [16]. Ventilation has a significant role in the evaluation of Thai houses. Due to the humid and hot climate, it is the only way to prevent mold and structural damages without chemicals. It is also essential for a healthy and comfortable environment for users. Another important characteristic element serving this purpose is the gap between the top of the walls and the roof [17]. In the floor plans of traditional Thai houses, the terraces are the key organizers of the life of the users. Larger open spaces in the center or narrower verandas around the house under the overhanging eaves serve as transitional spaces [16].

The contemporary vernacular architecture of the region is still underestimated and weakly documented. According to the study of Punpairoj, it is an organic process which is a result of a community working together rather than the design of an individual architect. There are two opposite approaches of vernacular architecture: the "decline" or "revival" of them, using modern structures and materials to meet the requirements of today [3].

Projects such as the two small-scale houses of this case study are opportunities to find new possible approaches for contemporary architecture, inspired and influenced by local technologies and culture. The significance of them lays both in their design and community-building effect, which can make a huge difference for both builders and users. This cooperation is, however, crucial, as it guarantees to avoid alienating and forced designs, which are not sustainable, mainly because the community has no connection to it.

\section{Results-Case Study}

"The body image [...] is informed fundamentally from haptic and orienting experiences early in life. Our visual images are developed later on, and depend for their meaning on primal experiences that were acquired haptically" [18]. The analysis of the next two case studies is based on the above aspects, focusing on their functionality, actual usage and connections to their physical, social and built environment. Their geometry, technical design and ecological features were taken into consideration, in addition to decoding their dimensions according to anthropometric data for each age group, through their published plans, on-site construction photos and structural details from the architects. 


\subsection{Safe Haven-How It Started}

Tasanee Keereepraneed is a local woman living in the heart of Thailand, in Ban Tha Song Yang, which is about a two-hour bus ride away from the Burmese border. Since 1987, she has been caring for orphans. Together with her brother, they now care for about 60 children who came from the surrounding areas of Thailand and Burma. They provide housing, full care, medical assistance and education to these children, supporting themselves with the help of volunteers and donors, as well as NGOs. Most of the children were orphaned by the Burmese political crisis and military dictatorship [13]. The age of the residents ranges from 0 to 20 years. Different age groups eat, study and play together, much like in a family environment. From an early age, they are also taught responsibility and housework appropriate to their abilities, in addition to elementary education. The primary goal is for children of typically Burmese descent to acquire Thai citizenship as adults. In addition, an important element of education is a loving, inclusive atmosphere [19], which is the key to a more peaceful future in the region. The orphanage has been built in several phases, depending on the actual needs and incoming offers. The founding siblings, who themselves had lost their parents early on, converted the inherited parental home for their protégés. Their future plans include the development of a drinking water supply system, dormitories with additional beds and the construction of a health center [13]. In recent years, however, two remarkable buildings have been built on the site. The Library and the Bathhouse were created through volunteer work, and they are important steps for the future of the home, despite their small size.

\subsection{Background of the Design}

In 2009, TYIN Tegnestue, a non-profit humanitarian organization, invited architects Sami Rintala and Hans Skotte, as well as 15 architecture students studying in Norway, to realize two buildings together, both made of traditional, local materials [20]. The small buildings create value beyond their functionality: they serve the physical and mental health of those living here. These projects represent an architectural approach that relies on local materials and building traditions and does not function as a kind of top-down 'design aid package', but rather lifts up a highly vulnerable group in the long run with real results.

In a tropical climate such as that of Thailand, the key to preventing epidemics is collective and personal hygiene, which is served by the bath. It was built next to a young teak plantation. The toilets are enclosed in two rooms covered with red and yellow plaster. In addition to the traditional one, there is also a flush toilet inside. Between the two is located the bathroom, opening up to the forest area, which is a culturally accepted solution in the area. Openness, however, is often used as a tool to promote children's safety and well-being in Western civilizations, too [21]. This "porch", covered with bamboo shading, combines different functions. On the site, there is no sewerage, but at the same time, it is often flooded by torrential rains Therefore wastewater treatment and keeping the surfaces clean was a great challenge. An important element of the project is the easy-towash and quickly drying, ventilated floor and the closed drainage of wastewater led into underground desiccators (Figure 2).

While the bath serves primary physical and infrastructural needs, the library is a place for children to develop mentally in order to break out of the spiral of poverty. It opens up opportunities for culture, education and self-education, while encouraging socialization and individual development as well. It serves as a library, playground, classroom and meeting point at the same time. Since internet access is only possible from here, it literally opens the door to the world. Under the roof are computers on one side and the actual library on the other. Among them is a gateway-a transition area-where the rocks of the terrain were included into the concept by the creators, serving as stairs. This is the point where students leave their slippers or shoes behind before entering the building, which is a local tradition. The concrete walls made on site embrace rows of bookshelves. Inspired by traditional construction methods, the natural appearances of the materials are preserved, if possible. At the corner, shelves take a turn and form a stairway to the airy, 
quiet attic. The wooden floor, with its level raised from the ground serves as a platform for the 'classroom', but also works as a seat during outdoor activities. It was made with a slightly tilted carpentry structure, shaded by bamboo slats, letting in soft light and fresh air.

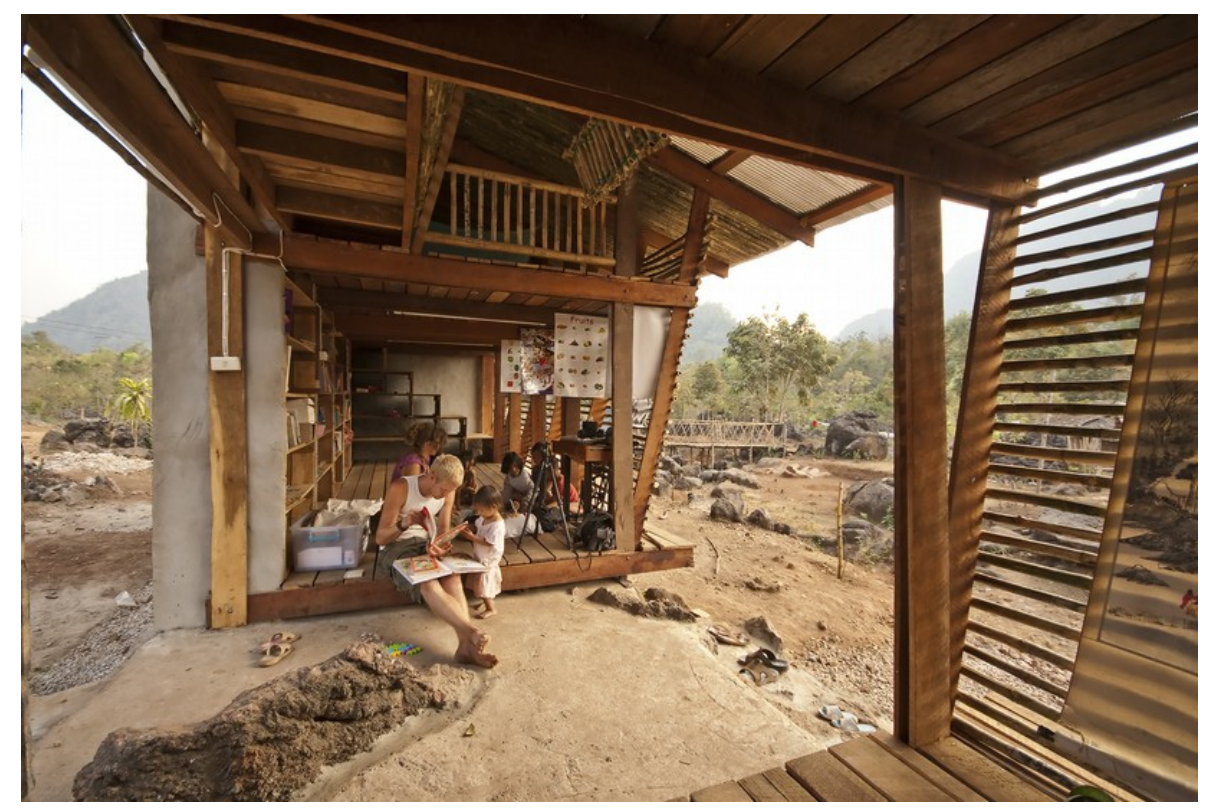

Figure 2. Interior of Library. Photo of Safe Haven Library, photo: Pasi Aalto, architecture: TYIN Tegnestue (Andreas G. Gjertsen, Yashar Hanstad), Available online: http:/ / www.tyinarchitects.com/ download/works/2009_safehavenlibrary/01_safehavenlibrary_photos_hires.zip (accessed on 13 July 2021).

\subsection{Analysis of Ergonomic Aspects}

From Pallasmaa's point of view, the fundamental task of architecture is to restore the human-nature relationship, in this way improving the mental well-being of the users [6]. To achieve this, the building does not draw a sharp line between its user and the environment, thus connecting the two instead of separating them. Still, it provides adequate protection for people. Due to permissive local regulations, the designers had excessive freedom during the design process, therefore, they could focus on the local traditions and climate

These design decisions influence the whole lives of the children growing up here now or in the future. For the right architectural solutions, the creators and builders had to get to know the community, its unique needs and difficulties. Knowledge of the local culture facilitates a mentoring system among children and helps them integrate into society. A lack of regulations made it possible to involve users-children and adults alike-in the design and construction. With this, the two buildings not only serve their needs better, but the building process has become part of the history of the community. This fundamentally determines their relationship to the buildings. Since the projects are located within the enclosed area of the orphanage, they could open up to their surroundings. Children use the area freely (according to a defined agenda, of course), so openness serves the function well and does not raise security issues.

\subsubsection{Anthropometry and Functionality}

One of the primary aspects of ergonomics is anthropometric sizing, which serves as the basic usability and functional issues. Available anthropometric databases were examined for this analysis (Table 1) [22,23]. The database is a result of a survey from several countries around the world, with data from Japan, China and Sri Lanka from the Far East region. However, due to the nature of the examined projects (manual construction and usage of materials found on site), the dimensional accuracy of the implementation shows greater differences than the differences that can be discovered in the database between the 
individual ethnic groups. Furthermore, given that all ages are present in the children's group, there was no specific age range to size objects for. Thus, local characteristics are more relevant in adult sizing, for which data from the region were used.

Table 1. Example of anthropometrical data.

\begin{tabular}{|c|c|c|c|c|c|c|c|}
\hline Age & Gender $^{1}$ & Height $^{2}$ & $\begin{array}{l}\text { Reach } \\
\text { Range } \\
\text { above } \\
\text { Head }^{2}\end{array}$ & $\begin{array}{c}\text { Seat } \\
\text { Depth }^{2}\end{array}$ & $\begin{array}{l}\text { Lumbar } \\
\text { Height }^{2}\end{array}$ & $\begin{array}{c}\text { Step } \\
\text { Height }^{2}\end{array}$ & $\begin{array}{c}\text { Seat } \\
\text { Height }^{2}\end{array}$ \\
\hline \multirow{2}{*}{2} & $\mathrm{M}$ & 87.9 & 104.5 & 23.5 & \multirow{2}{*}{37.5} & 33.7 & \multirow{2}{*}{20.5} \\
\hline & $\mathrm{F}$ & 87.6 & 104.5 & 24.5 & & 34.3 & \\
\hline \multirow{2}{*}{3} & $\mathrm{M}$ & 95.1 & 113 & 25.0 & \multirow{2}{*}{41.7} & 39.7 & \multirow{2}{*}{23.0} \\
\hline & $\mathrm{F}$ & 94.2 & 112.5 & 26.0 & & 38.6 & \\
\hline \multirow{2}{*}{4} & $\mathrm{M}$ & 102.1 & 121.5 & 26.5 & \multirow{2}{*}{46.1} & 41.7 & \multirow{2}{*}{25.5} \\
\hline & F & 101.2 & 120.5 & 27.5 & & 41.5 & \\
\hline \multirow{2}{*}{5} & $\mathrm{M}$ & 108.6 & 130.5 & 28.0 & \multirow{2}{*}{50.7} & 47.0 & \multirow{2}{*}{27.0} \\
\hline & $F$ & 107.6 & 129.0 & 29.5 & & 45.1 & \\
\hline \multirow{2}{*}{6} & $\mathrm{M}$ & 116.2 & 139.0 & 30.5 & \multirow{2}{*}{54.7} & 50.4 & 29.5 \\
\hline & $\mathrm{F}$ & 115.1 & 138.0 & 31.0 & & 52.1 & 29.0 \\
\hline \multirow{2}{*}{7} & $\mathrm{M}$ & 120.8 & 147.5 & 32.5 & \multirow{2}{*}{58.2} & 52.6 & 31.5 \\
\hline & $\mathrm{F}$ & 120.12 & 145.5 & 33.5 & & 54.1 & 31.0 \\
\hline \multirow{2}{*}{8} & M & 125.4 & 155.0 & 34.0 & \multirow{2}{*}{61.5} & 54.8 & 32.5 \\
\hline & $\mathrm{F}$ & 124.4 & 153.5 & 35.5 & & 57.3 & 33.0 \\
\hline \multirow{2}{*}{9} & M & 129.8 & 161.0 & 36.5 & \multirow{2}{*}{64.9} & 59.7 & \multirow{2}{*}{34.0} \\
\hline & $\mathrm{F}$ & 130.2 & 161.5 & 38.0 & & 59.4 & \\
\hline \multirow{2}{*}{10} & $\mathrm{M}$ & 135.0 & 168.0 & 38.0 & \multirow{2}{*}{67.6} & 61.0 & 36.0 \\
\hline & $\mathrm{F}$ & 135.6 & 17.5 & 40.0 & & 61.9 & 36.5 \\
\hline \multirow{2}{*}{11} & M & 139.13 & 174.0 & 39.5 & \multirow{2}{*}{71.3} & 62.8 & \multirow{2}{*}{37.5} \\
\hline & $\mathrm{F}$ & 142.45 & 176.0 & 41.0 & & 63.6 & \\
\hline \multirow{2}{*}{12} & $\mathrm{M}$ & 145.22 & 183.5 & 41.5 & \multirow{2}{*}{73.6} & 65.2 & 39.0 \\
\hline & $\mathrm{F}$ & 148.1 & 183.5 & 43.5 & & 66.8 & 38.5 \\
\hline & $\mathrm{M}$ & 150.7 & 190.5 & 43.5 & & & 40.5 \\
\hline 13 & $\mathrm{~F}$ & 151.7 & 189.0 & 44.5 & 75.5 & 65.8 & 39.0 \\
\hline & $\mathrm{M}$ & 158.5 & 199.0 & 46.0 & 76 & & 42.5 \\
\hline 14 & $\mathrm{~F}$ & 154.3 & 193.0 & 45.5 & 76.5 & 66 & 39.5 \\
\hline 15 & $\mathrm{M}$ & 162.8 & 206.0 & 48.0 & 770 & 7 & 43.0 \\
\hline 15 & $\mathrm{~F}$ & 156.0 & 196.0 & 47.0 & 77.2 & 66.7 & 40.0 \\
\hline 16 & $\mathrm{M}$ & 166.1 & 210.0 & 49.0 & 700 & 100 & 44.0 \\
\hline 16 & $\mathrm{~F}$ & 158.1 & 196.5 & 48.0 & 78.0 & 68.8 & 40.5 \\
\hline 17 & $\mathrm{M}$ & 168.7 & 212.5 & 49.5 & 700 & co 1 & 44.5 \\
\hline 17 & $\mathrm{~F}$ & 158.8 & 197.0 & 48.0 & 78.0 & 68.1 & 40.5 \\
\hline 10 & $\mathrm{M}$ & 169.0 & 215.0 & 50.0 & 707 & co 1 & 44.5 \\
\hline 18 & $\mathrm{~F}$ & 155.0 & 197.0 & 48.0 & 78.7 & 68.1 & 40.5 \\
\hline
\end{tabular}

${ }^{1} \mathrm{M}$-male, $\mathrm{F}$-female. ${ }^{2}$ Data given in $\mathrm{cm}$. 
For the above reasons, in the bathhouse (Figure 3a-c), only the toilets are indoors. The building provides enough cover for the urinals on the north side. Placed at three different heights $(45,55$ and $65 \mathrm{~cm})$, they are suitable for growing kids from the age of about 5 . Smaller children or children in need of help can use the traditional toilets located indoors. The advantage of these is the floor-mounted design, as smaller children are able to use them alone or with minimal help, unlike the higher wall-mounted flush toilets. However, such an item was also established for children to get used to that design, too. The cabins have a size of $125 * 140 \mathrm{~cm}$, so there is enough space (approx. $60 * 60 \mathrm{~cm}$ ) for the caretaker during use. The shower and washing machine are also in a lockable unit-the latter had to be protected from tropical showers and connected to electricity. The shower cubicle is $70 * 125 \mathrm{~cm}$ in size with a built-in design. This makes it easier for helpers to access, as there is no edge, no obstacle and no risk of accidents. The lamella cover provides safe limits for the space but does not close it. By learning to use Western-type toilets and showers, they can later easily adapt to the culture of either the city or other parts of the world. In addition, given the spacious area, it is possible to bathe more than one child at the same time, which is culturally accepted at the area.

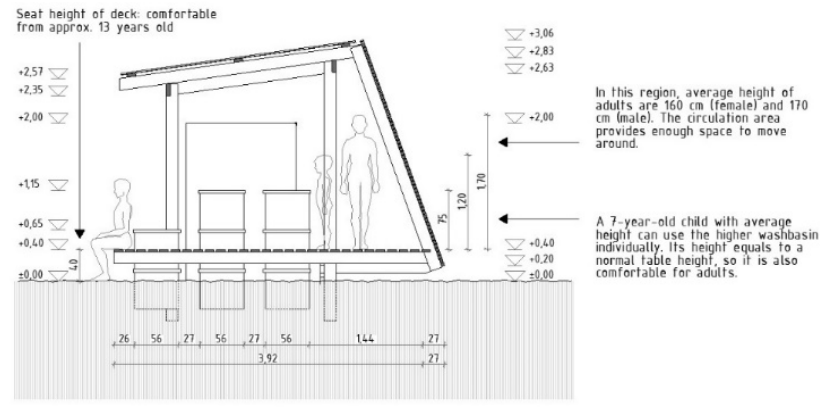

(a)

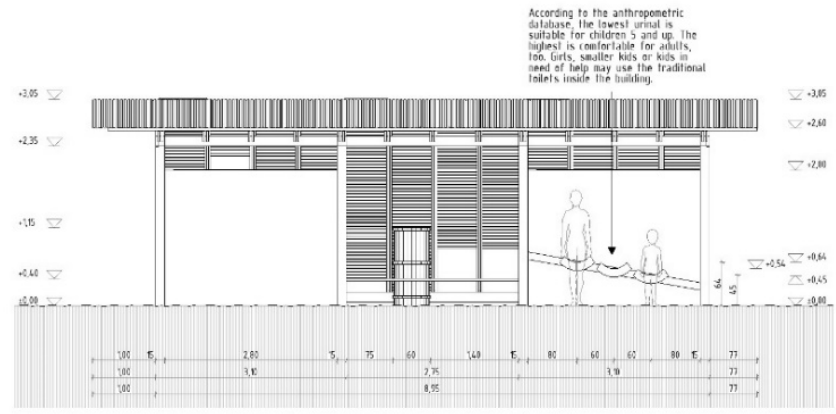

(b)

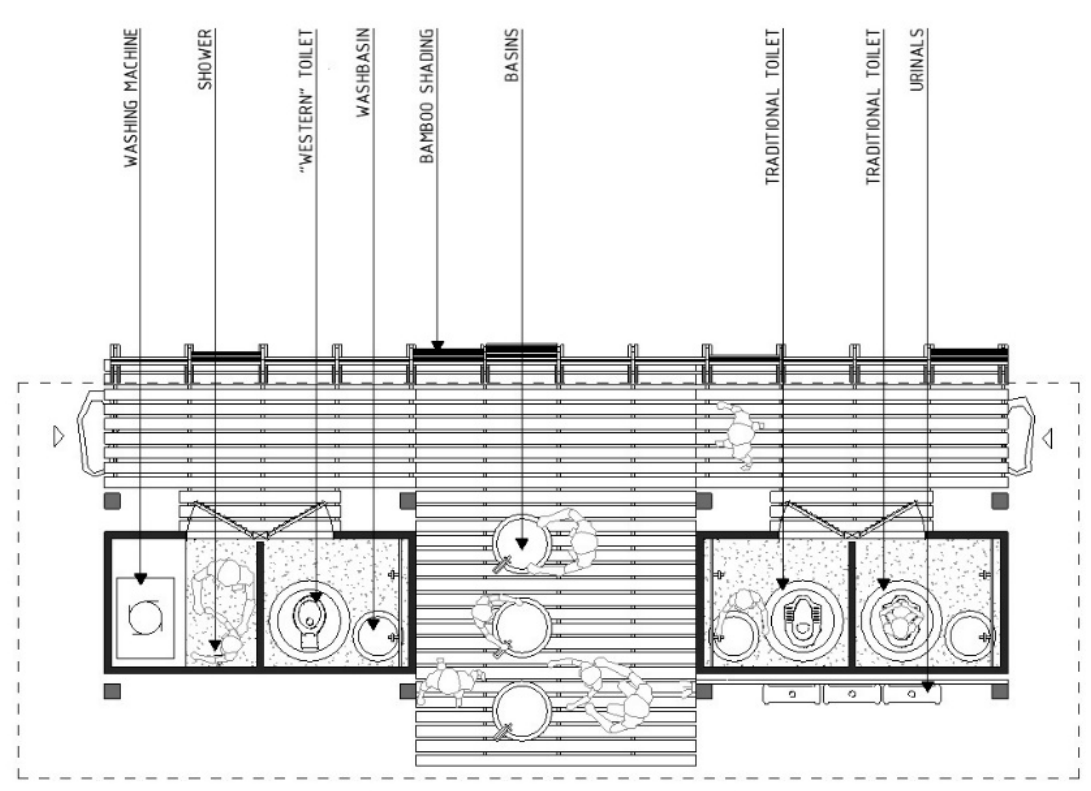

(c)

Figure 3. (a) Cross-section of Bathhouse; (b) elevation of Bathhouse; (c) floor plan of Bathhouse. Figures: Own drawings of the author (Mizsei, A.) based on TYIN Tegnestue Architects (Andreas G. Gjertsen, Yashar Hanstad), Available online: http:/ / www.tyinarchitects.com/ (accessed on 13 July 2021). 
Daily bathing routine and washing hands takes place on a light-structured wooden deck between the two closed parts of the building, with three washbasins of different heights. These are actually garden taps for which the "well" was built of large diameter reinforced concrete channels, protected by a grid on top to prevent children falling in. These elements have different heights: a 25-cm-high lower bowl and two others with height of about $75 \mathrm{~cm}$. Washbasins in the middle can be used for hand washing without any help needed, and with the different sizes, even smaller kids can start using them independently, without help. The space around them $(275 * 380 \mathrm{~cm})$ is enough for the caregivers to organize the bathing either individually or in small groups of children. The washbasins are standing free, in the middle of the space, so there is still a $60-\mathrm{cm}$-wide lane for the access of cabins. A minimum of the same width is available in the covered, side-open traffic in front of the cabs. This way, the functions can be used simultaneously.

In the case of the library building (Figure 4.), the application of a 35-cm module size was used. It is ideal for storage, but has further features, as well. The shelves surround the space and at the end of the building form a stairway which children can climb on. They can access the attic from here or use the stairs as seats for the preschool and primary school age group. At the same time, the floor, raised $45 \mathrm{~cm}$ above the ground, adapts to the seat height of adults, making it suitable to sit on while observing and supervising outdoor play. Thus, the adult may be present, but stay in the background only for safety reasons or necessary intervention. The interior is comfy with a large carpet. A free area of about $2 * 5 \mathrm{~m}$ is enough for up to 30 children. In the other side, however, computer workstations were established with traditional desks and chairs. There is enough space behind the two workplaces for the instructor to supervise and help.

An important and special part of the construction is the attic, which is a great option for children to retreat to, whether being alone or in small groups-with a sibling or a good friend. Of course, it is also accessible and safe for adults: the height of $60-135 \mathrm{~cm}$ allows for younger children to play and read comfortably while sitting, but it also remains accessible for older kids or adults, which is essential from a safety point of view and also necessary for maintenance and cleaning.

\subsubsection{Physiological Characteristics}

During the designing and building process, a number of aspects had to be taken into account, such as ecological considerations, financial possibilities and constraints, and the life expectancy, maintenance and repair of the two buildings. Important decisions had to be made for their whole lifespan in terms of safety and long-term accessibility and functioning. This includes not only the main functions, but also all future activities performed in, on or around them.

The floor of both buildings is made of local wood planks that are resistant to water if ventilated and dried out occasionally. Therefore, structures are lifted from the ground and the planks are built in with small gaps between them. It is a non-slipping, natural material, pleasant to touch and-similarly important-to smell, which was easy to assemble during a workshop organized with local volunteers and architecture students from all over the world. Later on, the planks can easily be replaced with simple tools by local workers. This is especially important for the bathing functions of the bathroom, where breakdown might happen faster. To avoid this and lengthen the lifespan of the structure, it opens up from the sides to ensure the flow of air. Meanwhile, partial shading creates a sense of protection and protects from the hot southern sunshine. Still, it allows enough sunlight to have a drying and disinfecting effect.

The buildings are located close to each other, near a traditional building, which functions as the kitchen and dining area. The examined buildings were also made using local materials, so the natural colors and textures of wood, bamboo and stone appear, thus ensuring cultural continuity and connection with the previous, traditional structures. These natural materials are environmentally friendly but also "human friendly": they are safe, they do not need toxic surface treatment or preservatives, they are easy to replace 
and provide durable surfaces. Their touch and sight blend the houses in the surrounding natural landscape and built environment. Bamboo has been used on surfaces that are particularly exposed to weather because it is more durable and even more easy to replace. In addition, it is lightweight, which minimizes the risk of accidents and simplifies construction and maintenance processes. Locally available natural earth pigments were used to color the surfaces.

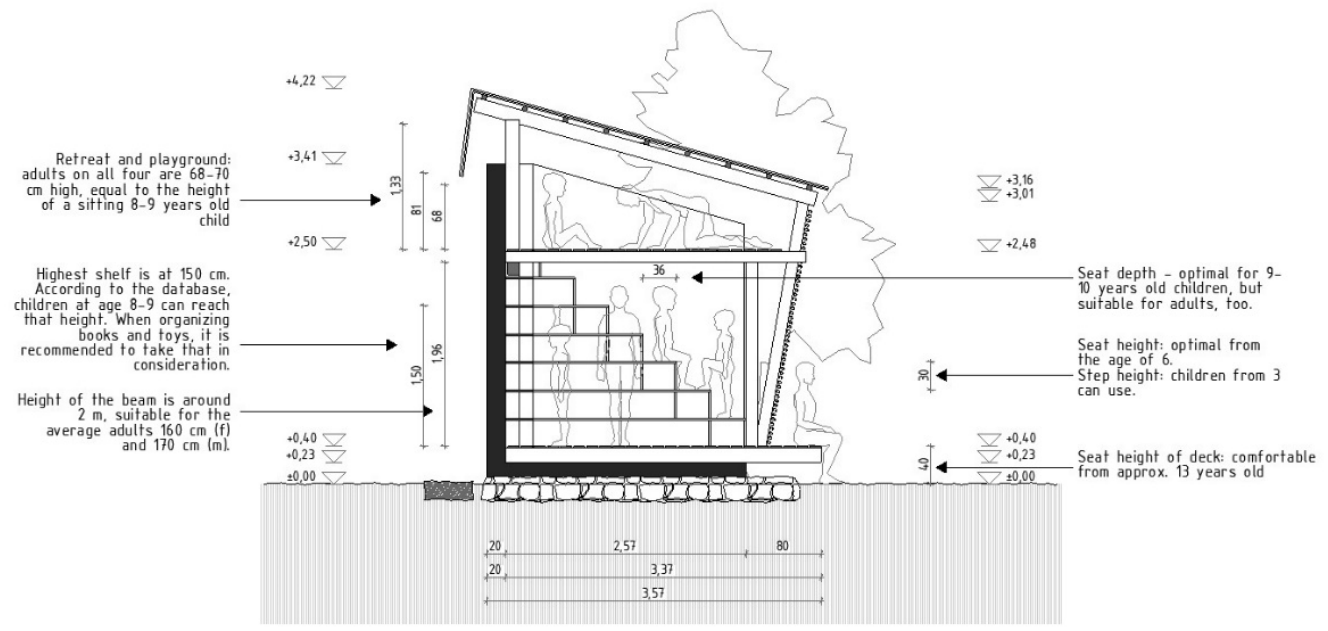

(a)

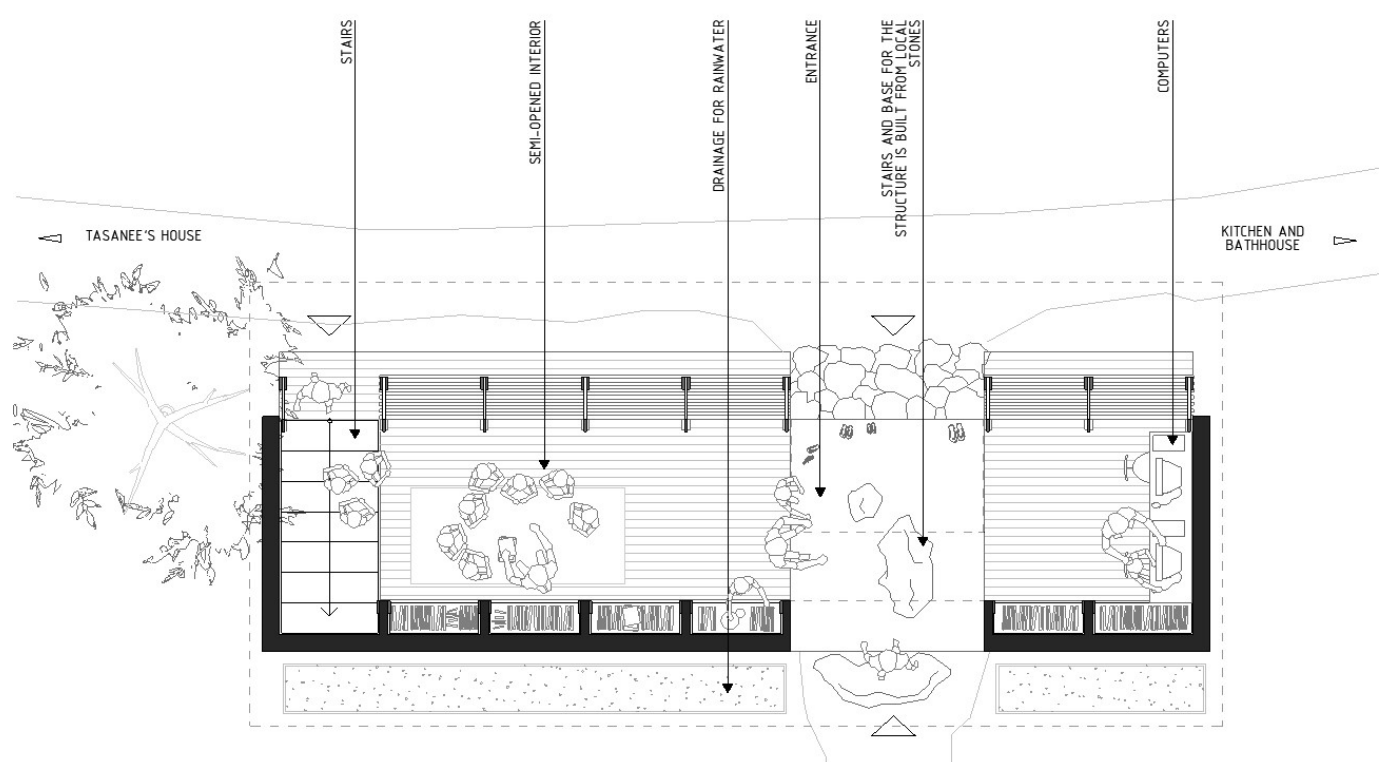

(b)

Figure 4. (a) Cross-section and (b) floor plan of the Library. Figures: Own drawings of the author (Mizsei, A.) based on TYIN Tegnestue Architects (Andreas G. Gjertsen, Yashar Hanstad), Available online: http:/ /www.tyinarchitects.com/ (accessed on 13 July 2021).

\subsubsection{Psychological and Cultural Aspects}

The loss of their home and family is a serious trauma for every child who has to survive such things. Far away from their homes, one of the most important tasks of Safe Haven is to help them heal from those experiences. The spatial system, materials and colors of the examined buildings are suitable for creating objects and places to connect to [24], slowly taking over the role of the home in the lives of the children. Aspects of this are examined in this chapter (Figure 5). 


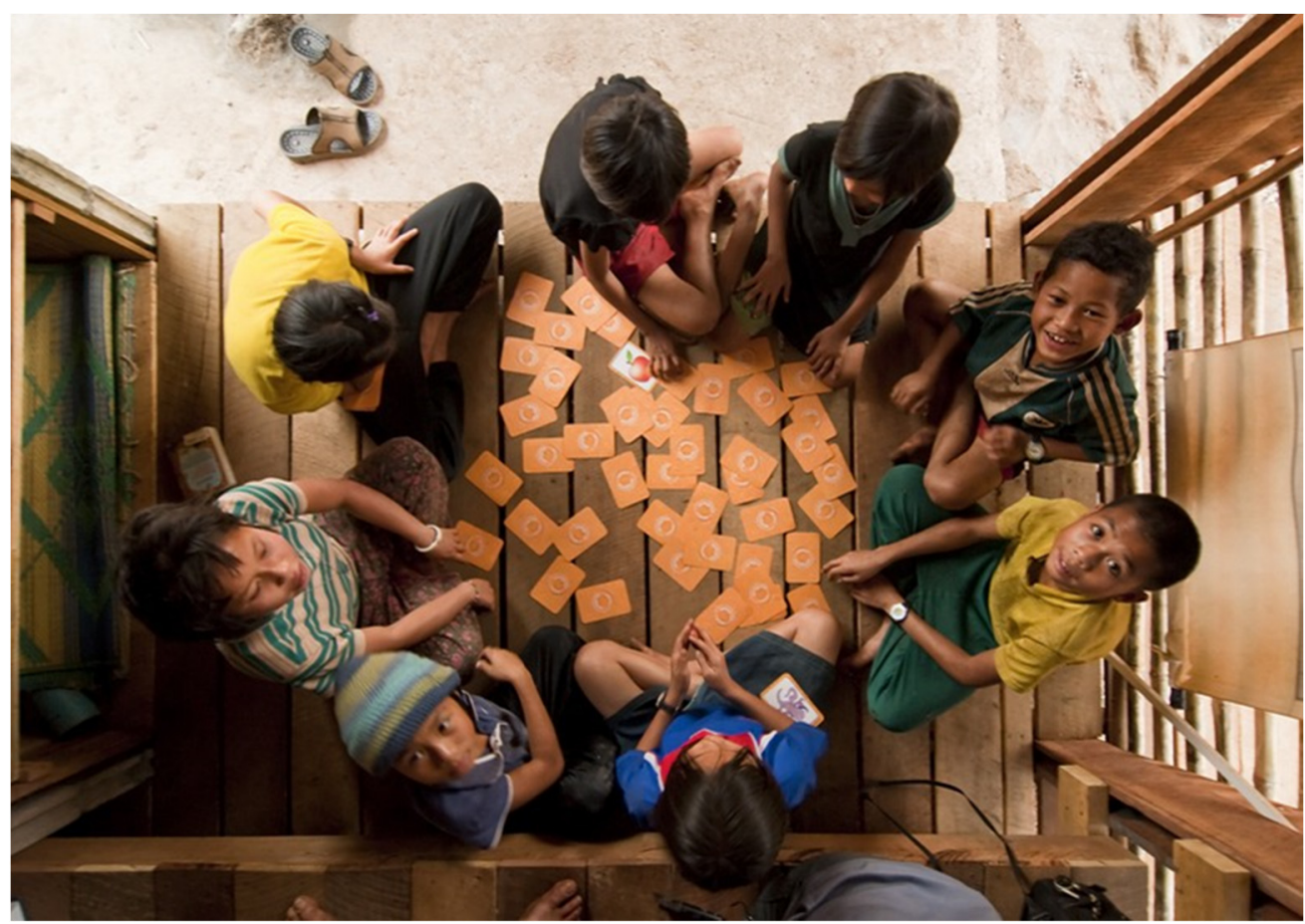

Figure 5. Group of children playing in the Library building. Photo of Safe Haven Library, photo: Pasi Aalto, architecture: TYIN Tegnestue (Andreas G. Gjertsen, Yashar Hanstad), Avail-able online: http://www.tyinarchitects.com/download/works/2009_safehavenlibrary/01 _safehavenlibrary_photos_hires.zip (accessed on 13 July 2021).

The community of different age groups creates a special situation in the orphanage. In addition to being educated for their independent lives in the future, children learn to cooperate and help each other. This is why the projects analyzed here are in a special position. In addition to being inclusive for all ages and abilities, it is neither necessary, nor even desired to completely rule out the presence of a helping hand or caretaker in all cases. Older or more experienced children can share their knowledge with their younger peers, helping them until they can cope on their own. Its community-building and educational benefits are invaluable, not only for the recovery and development of traumatized children, but also for their later lives, when it comes to further education, workplaces or private life. Empathy is thus manifested in buildings on two levels: on one hand, their design responds sensitively to the users' problems, and on the other hand, they encourage desirable, empathic behaviors. Both the bathhouse and the library contribute greatly to these values.

Independence and the relationships between children and young people are of priority. However, adult management, supervision and attachment to caregivers are also important for the users. In the bathhouse, the little ones are helped to bathe by adults or their older "siblings". These are intimate moments when they receive the full, undivided attention of the caregiver. In addition, there are no tables or chairs in the library except for the two computer desks. The teacher and students sit in a circle on the floor or carpet, horizontally on the same level, forming a group. This horizontal system encourages personal connections and is being rediscovered nowadays in the Western world by democratic and alternative educational methodologies. In addition, the more flexible the space is, regarding its arrangement and usage, the less harm the constant sitting position makes on the posture of students [25]. Its significance is enormous when it comes to children who are cut off from the family environment. It gives children a family-like experience, strengthens the sense of belonging, encourage cooperation and acceptance of each other.

The use of local workers and building materials available in the area has resulted in architectural forms that are related to local archetypes. This makes them look "familiar" to 
the children, which will help to strengthen the children's identity and their sense of security. In addition to their physical and mental development, it provides cultural continuity. Given their past injuries, this is particularly important for this group.

Due to the open design of the small library, it connects to a much larger area than its actual size. It is a central point in a free area, where community life and games flow around it freely. Similarly, in local building traditions, outdoor and transitional spaces also have a great significance: most activities throughout the day take place outside the house. Moreover, the interior usually has a direct visual connection to the exterior, as traditional Thai buildings are not enclosed by walls, but only roofs and floors [16]. Arriving from the outdoor activities, the building welcomes children between the two wings of the building, where they can prepare for joining the quieter, organized, guided classes covered and protected by bamboo blinds. The function of the attic is to provide shading and ventilation, in addition to offering children a private playground and their own space. The significance of these nooks for them is huge in the long run: they are imprinted into their memories, and they improve their perception of space and their own place in it. For those who have lost a home, such spaces can restore their attachment to places.

When it comes to colors, the two buildings work together. Wood, bamboo and locally found stones remained untreated, with a natural, rustic appearance-another important feature of building traditions of the region [17]. The walls built from concrete blocks are plastered and given a slight coloring: yellow and red appear on the bathhouse, and a natural, cooler, blue-gray shade on the library. In addition to its playful sight, the reason behind the difference lays in function. The bright colors of the bathhouse not only refresh the body but also enliven the spirit and slightly increase the feeling of warmth. Blue appears as a calming contrast. In the library, the cool, soothing shades help kids to focus. Books, toys and fabrics are enough of bright colored spots in the library. The softness of wood, bamboo, textiles and paper also provides the small study room better acoustics, which helps to focus attention and transforms learning into a pleasant daily activity.

\section{Discussion}

In the two projects of the case study (Figure 6), the creators also step back to simple solutions: orientation, lighting and creating a good microclimate. Meanwhile, they create "pleasant" places for the community, as one of the essential elements of sustainability is that users love the building so they can and want to use it for as long as possible. Recognizing that the main problem is not energy supply-energy is available almost indefinitely from different sources-the real problem is waste generation. It responds to minimize this with a timeless design and proper material selection. With these fundamentals, he follows the ideas of Pallasmaa, who preferred the "living" materials of traditional cultures and the humanistic scale to the abstract and universalizing effects of modern technology [11].

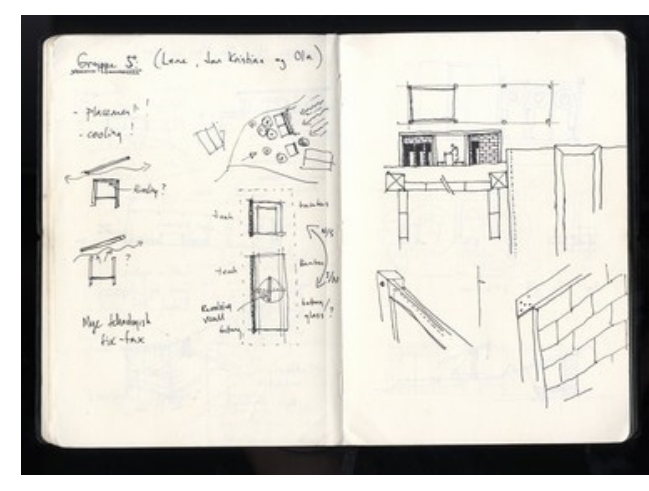

(a)

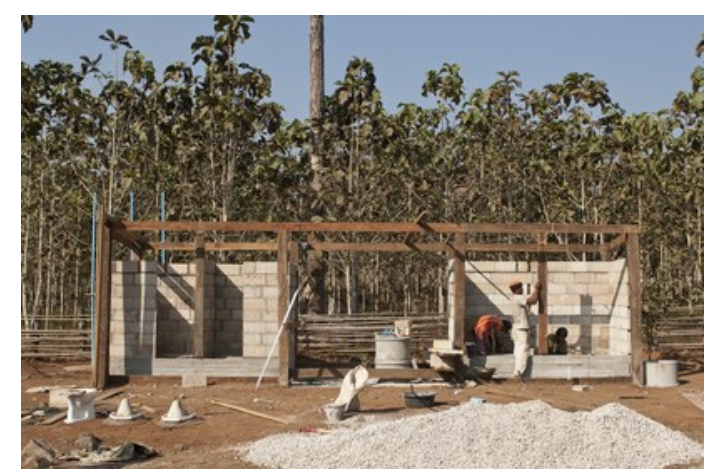

(b)

Figure 6. (a) Design on site-sketches. (b) Community building.Sketches of the designers and photo of the building process TYIN Tegnestue Architects (Andreas G. Gjertsen, Yashar Han-stad), Available online: http:/ /www.tyinarchitects.com/ downloads / (accessed on 14 July 2021). 
In addition to their theoretically grounded approach, the construction and realization played an important role in the design. Being from all over the world, the architects did not design the buildings in advance, but did so "in situ" after getting to know the culture and building traditions, as well as considering the available sources, local conditions and climate. The final design was chosen after a few days of workshops. This way, they could ensure cultural continuity through their "gentle" intervention. This chapter is to detail connections and similarities to local building practices and point out any differences.

\subsection{Orientation and Place}

Traditionally, Thai inhabitants settled in smaller farming communities, with buildings organized around a common space [16]. The orphanage follows this pattern with different buildings for different functions loosely inhabiting the field. The two buildings fit into this concept, with their individual pavilion-like appearance (Figure 7).

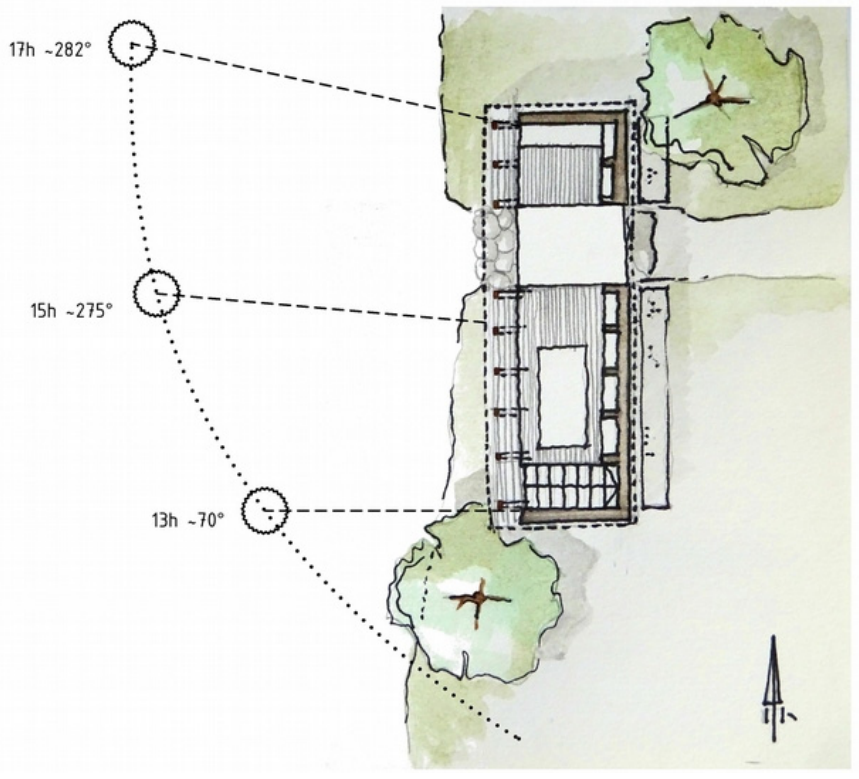

(a)

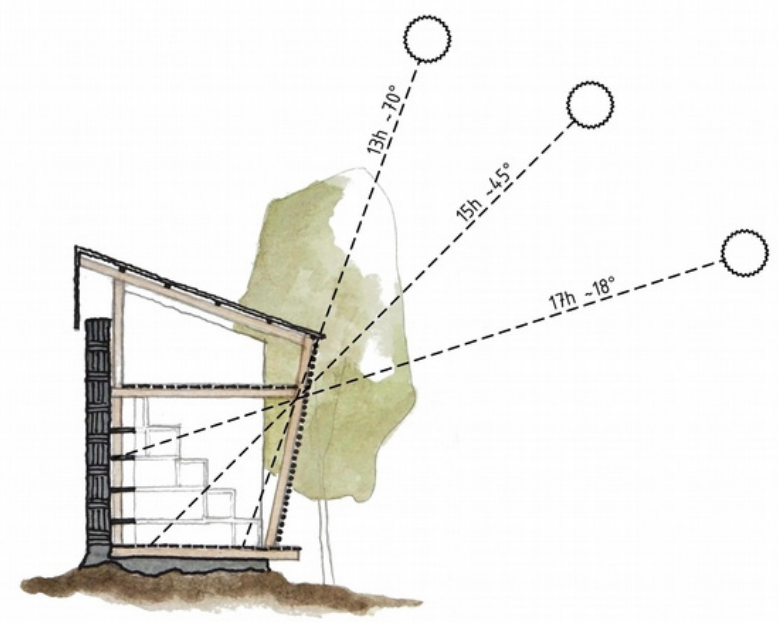

(b)

Figure 7. (a)Library floor plan sun path. (b) Library section, sun path. Sketches of san path, based on TYIN Tegnestue Architects (Andreas G. Gjertsen, Yashar Hanstad), Available online: http:/ / www.tyinarchitects.com/ (accessed on 23 August 2021). 
Mostly, regional Thai houses were oriented lengthwise in an east-west direction. This way, they could avoid excessive heating from the sun [16]. The library is oriented exactly this way. Large openings to the west provide enough light throughout the day and lets in the most direct sunlight in the evening, so they can use the building for as long as possible.

However, there are examples of traditional houses, especially in the north [16] where the climate is less hot and temperature fluctuates more daily, that are oriented south-north. However, the area of the orphanage lays in Central Thailand, with relatively hot and humid weather, and the main usage of the bathhouse takes place in the mornings and evenings. In addition, due to its function, structures are more prone to dampness and mold. Facing to the south, structures can easily be dried up by the strong solar radiation, working as a natural disinfectant (Figure 8).

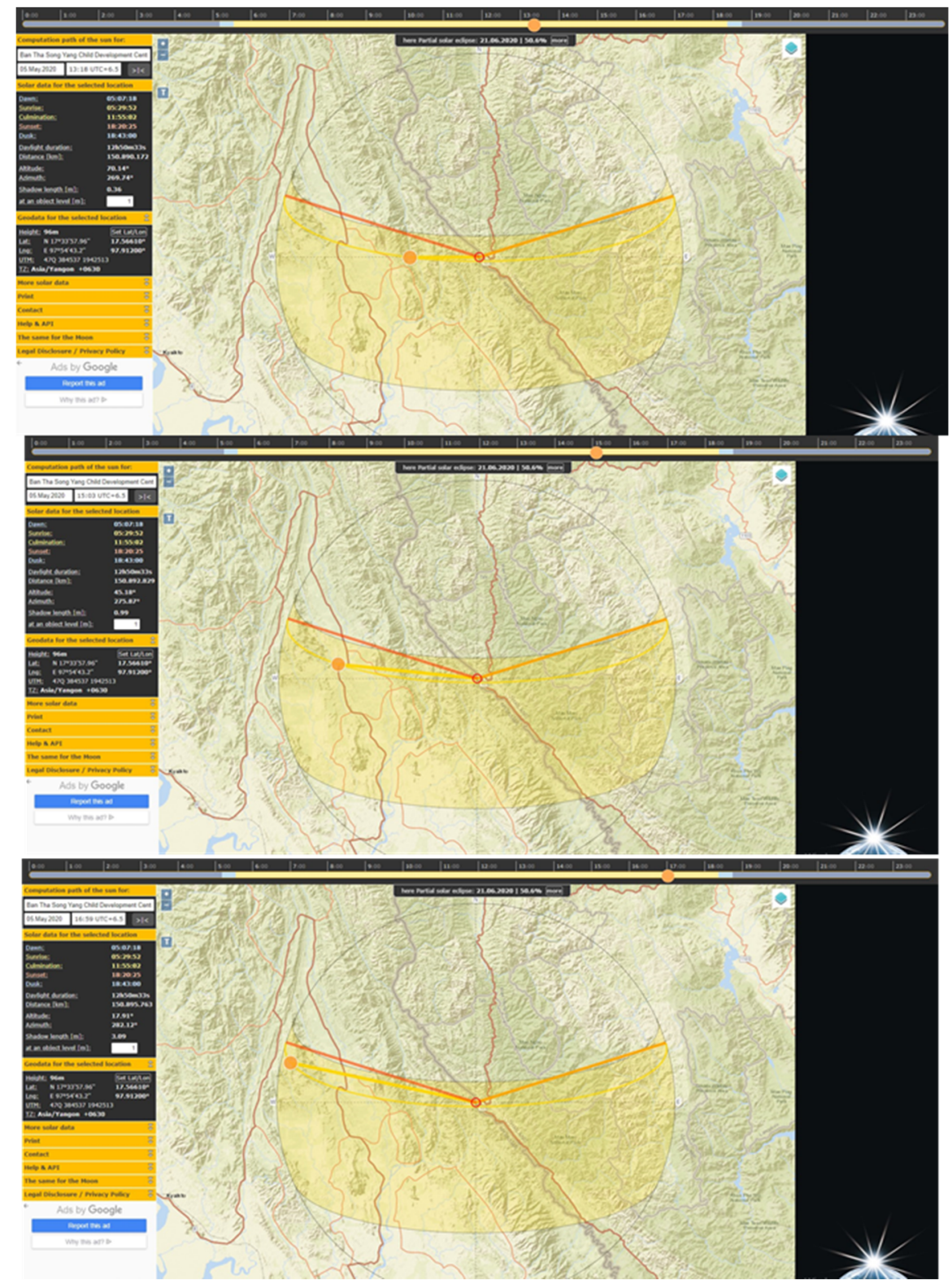

Figure 8. Sun path diagrams at 13:00, 15:00 and 17:00 at the location. Sun path diagrams. SunCalc.org, Available online: https:/ / www.suncalc.org/\#/17.5661,97.912,18/2021.08.23/15:15/1/3 (accessed on 23 August 2021). 


\subsection{Spatial Organization}

Both buildings follow some basic principles of traditional Thai architecture. Maybe the most important is that both have an open terrace in the centre and verandas under the roof. Such transitional spaces play an important role of daily life in Thai culture and therefore important in the socialization of these children.

The buildings also have large openings and visual connection to the exterior, which is also an important principle of regional architecture. Floor levels are lifted, standing on stilts, providing a seat: "In this pattern of local Thai culture, the act of sitting or lying down on wooden floorboards became a feature of the normal lifestyle. As explained, the steps between the platforms in the houses were used for eating, resting or sleeping in order to obtain the benefit of the natural cool breezes passing through the space underneath" [16]. Bamboo shadings protect the interior without enclosing it hermetically. Life can flow in and around the houses uninterrupted.

Usually, the ground floor is used for the main functions of regional buildings, with the attic serving only as a buffer zone or storage. In the case of these projects, only the library has an attic, which is for storage and serves as a zone for children to climb and play. The main library and educational functions remain downstairs.

Traditional Thai houses have around $40 \%$ of their floor area as terraces (open or semi-open transitional spaces) and up to $60 \%$ with the veranda areas added [3]. Those proportions, of course, are a bit different due to the functions and usage of the buildings: more for the bathhouse and a bit less for the library.

\subsection{Structures, Materials and Building Process}

Permanent structures in Thailand are usually made of wood. For semi-permanent or temporary ones, on the other hand, bamboo is used more commonly [3]. A basic feature is that all regional buildings have a lightweight structure and wooden plank walls where necessary. However, in the last 20 years, masonry blocks and concrete also have been used in an attempt to follow Western patterns, in spite of the fact that they cannot provide the advantages that traditional, ventilated structures do. However, according to [2], these houses "benefit from the massive construction in a region where night temperatures often drop below the comfort zone, and there is a larger diurnal temperature swing" [2].

Both buildings analysed here are kind of a hybrid structure, with solid walls enclosing parts of them or specific functions, such as toilets or bookshelves. This way, the designers and builders could balance between modern masonry structures and traditional appearance and technology. In fact, they managed to benefit from both by appropriately deciding the proportions and disposition of each. The massive blocks create the core of the structure with the wooden roof "floating" above it, using the traditional method of creating a gap between walls and roofs to let air and light in. Stilts are kept quite low, as children need easy access to the buildings; still, they benefit from the cooling effect of air under them.

One reason, that solid walls and structures slowly started to displace traditional structures are the costs. Both timber and the labor cost of professional vernacular carpenters are not affordable for low-income village people or-as in our example-for an orphanage financed from donations. These two buildings are good examples that needed no advanced craftsmanship and could be realized by volunteers from materials available around. Still, they do connect to traditional architecture of the region.

\section{Conclusions}

To sum up, this study gives an overview of the traditional and contemporary vernacular architecture of Thailand and the problems that the loss of traditional knowledge causes. It is also an attempt to reveal the ergonomic aspects of traditional architecture, pointing out the specific ergonomic requirements for the environment designed for children and their caregivers. The buildings chosen for the case study are good examples of today's socially sensitive architectural approach, based on local materials, community building, and an ergonomic and ecological approach that works harmoniously both with the natural 
and the built environment. These two small-scale projects also demonstrate that a highly functional and ergonomic solution can emerge without strict regulations if created with the empathetic attitude of the creators and the involvement of end users.

In addition to their functionality, the aim of the buildings is to strengthen the users' identities and not estrange them from their own cultural heritage. This kind of approach is also beneficial for the participating architects and students, too, as they might also find a way to return to their own roots and seek local solutions in their practices later on. Projects and processes such as these therefore represent a great educational value in our overly technocratic world.

The most important outcome of this study is, therefore, that neither ergonomics nor sustainability should be examined without consideration of the local features of architecture and society. Contemporary design needs to acknowledge its characteristics: the only way to sustainability is following and organically evaluating traditional regional building technologies. This connection and the how incorporating more elements from traditional architecture and cultural attributes affect design methods, construction and community building might be a direction for future studies.

Author Contributions: Conceptualization, A.M. and P.G.H.; methodology, P.G.H.; writing-review and editing, A.M.; supervision, P.G.H. All authors have read and agreed to the published version of the manuscript.

Funding: This research received no external funding.

Data Availability Statement: Data used for this study available in the following publicly accessible repository, created and used for educational and research purposes: Norris, B. Childata: The Handbook of Child Measurements and Capabilities: Data for Design Safety; Consumer Safety Unit, Department of Trade and Industry, University of Nottingham: Nottingham, UK, 1995. Peebles, L. Adultdata: The Handbook of Adult Anthropometric and Strength Measurements: Data for Design Safety; Consumer Safety Unit, Department of Trade and Industry, University of Nottingham: Nottingham, UK, 1998.

Conflicts of Interest: The authors declare no conflict of interest.

\section{References}

1. Viaro, M.A. What is the situation of traditional architecture in Southeast Asia? Arch. Völkerkund. 2007, 57-58, 81-86.

2. Antarikananda, P.; Douvlou, E.; Mccartney, K. Lessons from traditional architecture: Design for a climatic responsive contemporary house in Thailand. In Proceedings of the PLEA 2006-The 23rd Conference on Passive and Low Energy Architecture, Geneva, Switzerland, 6-8 September 2006.

3. Punpairoj, P. Recalibrating the New Thai Vernacular Architecture. J. Archit./Plan. Res. Stud. 2011, 7, 65-79.

4. Attaianese, E.; Duca, G. Human factors and ergonomic principles in building design for life and work activities: An applied methodology. Theor. Issues Ergon. Sci. 2012, 13, 187-202. [CrossRef]

5. Fross, K. Ergonomics in the Practice of Project Architect on Selected Examples. In Human-Computer Interaction. Theories, Methods, and Tools. Lecture Notes in Computer Science; Kurosu, M., Ed.; Springer: Berlin/Heidelberg, Germany, 2014; Volume 8510, pp. 77-85.

6. Schumacher, E.F. Small Is Beautiful_Economics as If People Mattered; Harper Perennial: New York, NY, USA, 1989.

7. Rintala, S.; Eggertsson, D. Das Haus ein Instrument; FSB GmbH + Co KG: Berlin, Germany, 2015.

8. Remijn, S.L.M. Integrating ergonomics into the architectural design processes: Tools for user participation in hospital design. In Proceedings of the International Ergonomics Association 16th World Congress on Ergonomics, Maastricht, The Netherlands, 10-14 July 2006.

9. Aleksić, J. Healthy Architecture for Children. In Keeping Up With Technologies to Make Healthy Places, Places and Technologies; Fikfak, A., Lazarević, E.V., Fikfak, N., Vukmirović, M., Gabrijelčič, P., Eds.; PLACES \& Technologies: Nova Gorica, Slovenia, 2015; pp. 101-106.

10. Mohidin, H.H.B.; Ismail, A.S.; Ramli, H.B. Effectiveness of Kindergarten Design in Malaysia. Procedia Soc. Behav. Sci. 2015, 202, 47-57. [CrossRef]

11. Pallasmaa, J. The Eyes of the Skin-Architecture and the Senses; John Wiley \& Sons Ltd.: Hoboken, NJ, USA, 2008.

12. González-Díaz, M.J.; García-Navarro, J. Non-technical approach to the challenges of ecological architecture: Learning from Van der Laan. Front. Archit. Res. 2016, 5, 202-212. [CrossRef]

13. Safe Haven Orphanage. Available online: https://safehavenorphanage.org/ (accessed on 13 July 2021).

14. Tosi, F. (Ed.) Ergonomics in Design and Design in Ergonomics. In Design for Ergonomics, Springer Series in Design and Innovation; Springer International Publishing: Berlin/Heidelberg, Germany, 2020; Volume 2, pp. 909-911. 
15. Maurya, C.; Maurya, N. Ancient Indian Ergonomics Wisdom and Its Contemporary Significance. Theor. Issues Ergon. Sci. 2021. [CrossRef]

16. Tharavichitkun, B. Rethinking Thai Architecture and Cultural Identity. Ph.D. Thesis, University of Westminster Library, Westminster, UK, 2011.

17. Zune, M.; Rodrigues, L.; Gillott, M. Vernacular passive design in Myanmar housing for thermal comfort. Sustain. Cities Soc. 2020, 54, 101992. [CrossRef]

18. Bloomer, C.K.; Moore, C.W. Body, Memory and Architecture; Yale University Press: New Haven, CT, USA; London, UK, $1977 ;$ p. 44.

19. Mohd Radzi, A.N.; Ismail, K.; Ab Wahab, L. Ergonomics Concept in Inclusive Public Playground Targeting on Children with Disabilities. Environ.-Behav. Proc. J. 2020, 5, 3-9. [CrossRef]

20. TYIN Tegnestue Architects. Available online: http:/ / www.tyinarchitects.com/ (accessed on 13 July 2021).

21. Cliff, K.; Millei, Z.S. Biopower and the "Civilisation" of Children's Bodies in a Preschool Bathroom: An Australian Case study. Int. Soc. Sci. J. 2011, 62, 351-361. [CrossRef]

22. Norris, B. Childata: The Handbook of Child Measurements and Capabilities: Data for Design Safety; Consumer Safety Unit, Department of Trade and Industry, University of Nottingham: Nottingham, UK, 1995.

23. Peebles, L. Adultdata: The Handbook of Adult Anthropometric and Strength Measurements: Data for Design Safety; Consumer Safety Unit, Department of Trade and Industry, University of Nottingham: Nottingham, UK, 1998.

24. Jaglarz, A. Child-Friendly Kindergarten Bathrooms-Design Ideas. In Advances in Human Factors, Sustainable Urban Planning and Infrastructure. In Advances in Intelligent Systems and Computing, Proceedings of the AHFE 2017 International Conference on Human Factors, Sustainable Urban Planning and Infrastructure, The Westin Bonaventure Hotel, Los Angeles, CA, USA, 17-21 July 2017; Charytonowicz, J., Ed.; Springer: Cham, Switzerland, 2017; Volume 600. [CrossRef]

25. Pugo-Méndez, E.; Serpa-Andrade, L. Work in progress: Study of student ergonomics in classrooms based on posture monitoring. In Proceedings of the 2020 IEEE World Conference on Engineering Education (EDUNINE), Bogota, Colombia, 15-18 March 2020; pp. 1-3. 